\title{
The beginning
}

In Brazil, as in many other countries, it has been immensely difficult to establish a balance between national development and the investment in chemistry. It is still commonly thought that economic growth necessarily and justifiably entails the sacrifice of basic research. A change of mentality is required, with the more active and purposeful participation of industries, government and the scientific community, so that by the year 2000 scientific research may be managed realistically and effectively. A practical example of this policy is the publication of the Journal Brazilian Chemical Society by the ICI Brasil.

The editorial support that we received from ICI Brasil is proof of the company's interest in contributing to an improvement in scientific research and indisputably stands as an example to be followed by other private and governmental institutions.

Dr. Adrian Bromley, President of ICI Brasil, as well as John F. Mathews and Galdino Magalhães Vieira, former President and Director, respectively, gave proof of their personal commitment which was indispensable to undertaking. We are indebted to the support given by the Brazilian Federal Government through its Special Secretary of Science and Technology.

Our mission and our commitment are to the present and future generations, safeguarding the welfare of the world with the best of its chemistry research. Not just a new international Journal.

Eduardo M. A. Peixoto JBCS Editor IQ- USP 